\title{
Enhancement of Bioactivity of Natural Extracts by Non-Thermal High Hydrostatic Pressure Extraction
}

\author{
Hana Scepankova ${ }^{1} \cdot$ Margarida Martins $^{2} \cdot$ Letícia Estevinho $^{3,4} \cdot$ Ivonne Delgadillo $^{1} \cdot$ Jorge A. Saraiva ${ }^{1}$ \\ Published online: 29 September 2018 \\ (C) Springer Science+Business Media, LLC, part of Springer Nature 2018
}

\begin{abstract}
Natural extracts, like those obtained from medicinal herbs, dietary plants and fruits are being recognized as important sources of bioactive compounds with several functionalities including antioxidant, anticancer, and antimicrobial activities. Plant extracts rich in phenolic antioxidants are currently being successfully used for several pharmaceutical applications and in the development of new foods (i.e., functional foods), in order to enhance the bioactivity of the products and to replace synthetic antioxidants. The extraction method applied in the recovery of the bioactive compounds from natural materials is a key factor to enhance the bioactivity of the extracts. However, most of the extraction techniques have to employ heat, which can easily lead to heatsensitive compounds losing their biological activity, due to changes caused by temperature. Presently, high hydrostatic pressure (HHP) is being increasingly explored as a cold extraction method of bioactive compounds from natural sources. This non-thermal high hydrostatic pressure extraction (HHPE) technique allows one to reduce the extraction time and increase the extraction of natural beneficial ingredients, in terms of nutritional value and biological activities and thus enhance the bioactivity of the extracts. This review provides an updated and comprehensive overview on the extraction efficiency of HHPE for the production of natural extracts with enhanced bioactivity, based on the extraction yield, total content and individual composition of bioactive compounds, extraction selectivity, and biological activities of the different plant extracts, so far studied by extraction with this technique.
\end{abstract}

Keywords Natural extract $\cdot$ High hydrostatic pressure $\cdot$ Extraction $\cdot$ Antioxidant activity $\cdot$ Phenolic compounds

$\begin{array}{ll}\text { Abbreviations } \\ \text { HPP } & \text { High pressure processing } \\ \text { HHP } & \text { High hydrostatic pressure } \\ \text { HHPE } & \text { High hydrostatic pressure extraction } \\ \text { CE } & \text { Conventional extraction } \\ \text { HRE } & \text { Heat reflux extraction } \\ \text { LRT } & \text { Leaching at room temperature } \\ \text { UE } & \text { Ultrasonication extraction }\end{array}$

Jorge A. Saraiva

jorgesaraiva@ua.pt

1 QOPNA, Department of Chemistry, University of Aveiro, Campus Universitário de Santiago, 3810-193 Aveiro, Portugal

2 CICECO - Aveiro Institute of Materials, Department of Chemistry, University of Aveiro, 3810-193 Aveiro, Portugal

3 Agricultural College of Bragança, Polytechnic Institute of Bragança, 5301-855 Bragança, Portugal

4 Centre of Molecular and Environmental Biology, University of Minho, Campus de Gualtar, 4710-057 Braga, Portugal

\section{Introduction}

Oxidative damage of biomolecules (e.g., lipids, proteins, and DNA) plays a major role in the development of chronic and degenerative illnesses such as cancer, autoimmune disorders, aging, cataracts, rheumatoid arthritis, cardiovascular, and neurodegenerative diseases. The human body has several mechanisms to counteract oxidative stress by producing antioxidants, which are either naturally synthesized in situ, or externally supplied through foods, and/or supplements $[1,2]$.

The natural extracts of medicinal herbs, fruits, vegetables, spices, and others have been recognized as natural sources of antioxidants due to the presence of bioactive ingredients, including in most cases phenolic compounds [3]. Several studies have indicated that the plants containing a high-level of phenolic antioxidants possess a good range of bioactivities, including antioxidant, antiviral, antiinflammatory, and anticancer properties [4-6]. Moreover, they have shown higher antioxidant activity in vitro than vitamin $\mathrm{E}$, vitamin $\mathrm{C}$ as well 
as butylated hydroxytoluene (BHT), a widely used synthetic antioxidant $[7,8]$. Therefore, plant extracts rich in phenolics are currently being successfully used in several pharmaceutical applications and in the development of new foods (i.e., functional foods), in order to enhance the bioactivity of food products and to replace synthetic antioxidants $[9,10]$.

Total phenolics content is often considered as an indicator of the antioxidant activity of plant extracts [11, 12]. However, other studies have referred that the antioxidant activity does not necessarily always correlate with the level of total phenolics compounds, but sometimes with the content of particular individual phenolics [9]. For example, the antioxidant activity of pomegranate peel extract has been associated with the predominant phenolics in the form of ellagitannins, mainly ellagic and gallic acids, and punicalagin [13]. According to Guimarães et al. [14], the bioactivity of wild fruits proved to be more related to the phenolic compounds profile than to the amounts present in each extract [14]. It has been suggested that both phenolic content and antioxidant activity information must be discussed when evaluating the antioxidant/bioactive potential of extracts [9]. In fact, the levels of total and individual phenolics compounds vary depending on the plant parts used as starting material and can be altered by storage conditions and the extraction procedure [15].

The aim of an efficient extraction procedure is to provide the maximum yield of substances with the highest functional properties [16], enhance the bioactivity of the extracts, increase pollution prevention [17], and shorten extraction time [18]. However, most of the extraction techniques have to employ heat, which is most likely detrimental to the bioactivity of the extracts, due to heat promoted reactions [19]. The conventional extraction (CE) is time consuming and laborious, has low selectivity, and/or low extraction yield [20]. The combination of long extraction times and high temperature increases the chance of oxidation of phenolics which decreases the yield of phenolics in the extracts [7]. Moreover, the plant cell walls contain polysaccharides (e.i., cellulose, hemicellulose, and pectins) which act as barriers to the release of the intracellular bioactive compounds. Thus, alternative extraction methods, which are able to efficiently disrupt the cells and to recover these active secondary metabolites from raw plant materials are a key factor to enhance the bioactivity of plant extracts [21, 22].

Non-thermal high pressure processing (HPP), operating at room or at refrigeration temperature, is an alternative to thermal pasteurization with the advantage of providing foods with similar characteristics to the raw unprocessed foods [23], while retaining/improving important nutritive and functional properties [24]. HPP was recognized by the Food and Drug Administration (FDA) as an environmentally friendly technology and currently is being increasingly studied as a very promising cold extraction method of bioactive compounds from natural materials [25].
High hydrostatic pressure extraction (HHPE) is considered a good alternative in comparison to $\mathrm{CE}$ techniques, such as soxhlet, heat reflux, infusion, and distillation, since the extraction of compounds can be done in shorter time, the process may be performed at room temperature (avoiding thermal degradation of thermosensitive molecules), and it can improve the extraction efficiency in terms of higher extraction yields, less solvent consumption, and higher purity of the extracts [21]. Recently, it has been shown that HHPE has obvious superiority in obtaining higher quality of natural antioxidant substances [21], which can lead to the production of extracts with enhanced bioactivities [26]. The present paper aims to review the extraction efficiency of the HHPE based on the extraction yield, total content, and individual composition of bioactive compounds, extraction selectivity, and biological activities of the different plant extracts so far studied by extraction with this technique. It is important to highlight that this paper is focused specifically on the extracts instead of purified bioactive components, as some information regarding purified components can be found elsewhere [25, 27, 28].

\section{Extraction Process of HHPE}

The HHPE process is performed in a HHP processing unit (Fig. 1), basically consisting of a high hydrostatic vessel and the pressure generating system. The raw material is mixed with the appropriate solvent and hermetically sealed in a sterile high-density-polyethylene bag [29]. Furthermore, the samples are pressurized in the vessel of different volume ranges from $<8 \mathrm{~mL}$ (laboratory scale) to the current maximum volume reaching $525 \mathrm{~L}$ (industrial scale equipment) [30, 31]. In HHPE the hydrostatic pressure is applied in the range of 100 to $600 \mathrm{MPa}$ or even more, up to $1000 \mathrm{MPa}$ for short time periods [32].

The pressure is generated by pumping liquid medium (i.e., water in industrial equipment, silicon oil, ethanol, glycerol, or a mixture of these fluids with water in laboratory equipment) into the pressure chamber. When the desired pressure is reached, the pump is stopped and the pressure is maintained during the required holding time to extract and dissolve the active components by the solvent action, and then the system is depressurized [27].

\section{The Principle and Mechanism of HHPE for Enhancing Extraction of Bioactive Compounds}

One main advantage of using low/room temperature during HHPE results in the retention of thermo-sensitive components, such as bioactive compounds [33]. It is generally accepted that HHP mainly affects non-covalent bonds 
Fig. 1 Schematic diagram of an HHPE technique in an HPP unit (Courtesy of Hyperbaric Company). The sample material (e.g. fresh, dried, and powdered) is mixed with an appropriate solvent and hermetically sealed in a high-density-polyethylene bag. The sample is extracted in vessels under pressure in the range of 100-1000 MPa for a short time [28]

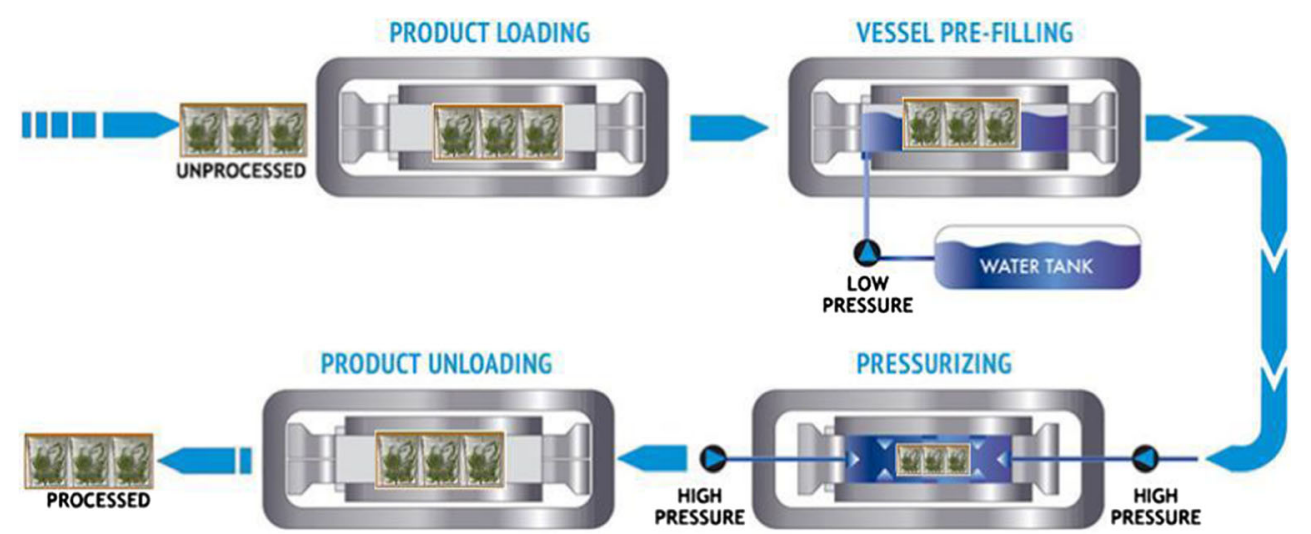

(hydrogen, electrostatic, Van der Waals, and hydrophobic bonds) [27], which means that low molecular weight compounds, such as many bioactive compounds (e.g., vitamins, pigments, flavor ingredients, flavonoids) are less affected [34, $35]$ and thus the HHPE treatment can preserve most of the bioactive compounds better [21]. The level of pressure is one of the most important parameters of the extraction process, due to its direct correlation with the solubility of bioactive compounds. Jun et al. [36] stated that increasing pressure increased solubility of the soluble constituents and enhanced the equilibrium concentration in the extract [36]. In a later study, the authors reported, that the pressure had direct mechanical effect on the disruption of organelle and blend of cellular contents [21]. When the pressure is released, the cell wall disrupts and releases the cytoplasm, which contains a high concentration of the target materials and removes them into the solvent. Both effects are thought as the major reason for the high efficiency of the HHPE method. To understand the structural changes involved in the HHPE, Fig. 2 displays the micrographs with structural features of untreated, HHPE and CE (reflux extraction) samples of Radix Angelica sinensis. After HHPE, the surface of the sample was greatly destroyed and the texture was crumbled (Fig. 2b), the tissue became porous and some micro-fractures and hollow openings were generated, while the surface of the CE sample (Fig. 2c) was complete and compact. Moreover, severe damage on cell walls and cellular organelles were observed after HHPE (Fig. 2e) while the CE sample remained, basically, unchanged (Fig. 2f). The destruction of cells and tissues by HHPE most probably facilitates mass transfer between cellular contents and the surrounding solvent and subsequently improves extraction efficiency [37]. The rate at which the pressure is applied and released is important for the cell rupture, thus a short extraction period is enough to harvest a highly concentrated extract [26]. Moreover, a recent study by Yan and Xi [21] refers that HPP pre-treatments can be a possible way to improve HHPE, since the former cause cellular disruption, favoring cell fracture by the latter [21]. The recovery of bioactive compounds in the HHPE process depends on processing factors like extraction pressure, temperature, time, type and concentration of solvent, and solvent-to-solid ratio, which are considered the main HHPE parameters [25]. For instance, the recovery of phenolic compounds from watercress was maximized when high pressure (600 MPa), high ethanol concentration $(100 \%)$ and short extraction time $(3.1 \mathrm{~min})$ were applied. The solvent was found to be the most relevant variable on the HHPE of phenolic compounds from watercress [38]. Indeed, different solvents can be used in HHPE; therefore, it is possible to extract compounds with different polarities differentially. The $\mathrm{pH}$ value of the solvent can be reduced during the HHPE leading to the enhancement of the extraction effectiveness of some bioactive compounds, such as, for instance, anthocyanins, since most of these compounds are more stable at $\mathrm{pH}<4$ [39]. Hence, the medium plays an important role in the extraction of bioactive compounds, but also in the antioxidant activity of the obtained extracts.

\section{Enhanced Antioxidant and Anticancer Activity of Natural Extracts by HHPE}

Some studies examined the optimal extraction conditions of HHPE in order to maximize the bioactivity of the natural extracts from different plant materials. The main parameters considered were extraction yield and total and individual content of bioactive compounds (mostly phenolic compounds), but also the extraction selectivity and the different biological activities of the extracts. The works so far reported in the literature, dealing with the biological activity of natural extracts obtained by HHPE, are presented in Table 1, including the extraction conditions used and the main results obtained that are discussed below.

\section{Green Tea Extract}

Green tea is increasingly popular worldwide, mainly due to its wide range of bioactive properties including antioxidant and anticarcinogenic effects. Studies have suggested that the most 

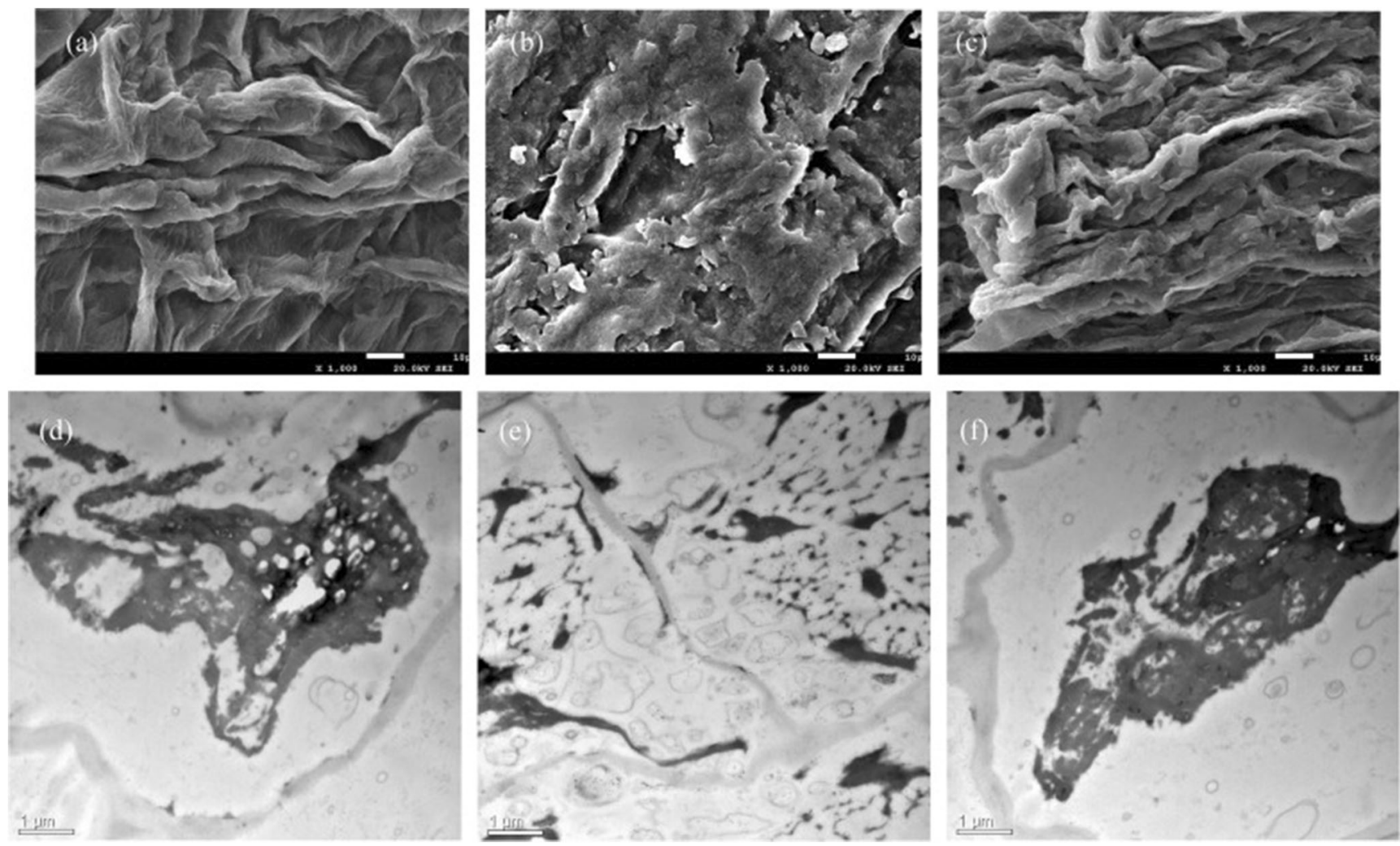

Fig. 2 Scanning electron micrographs ( $\mathrm{a}, \mathrm{b}, \mathrm{c}$ ) and transmission electron micrographs ( $\mathrm{d}, \mathrm{e}, \mathrm{f})$ of the untreated, HHPE and CE (reflux extraction) samples of green tea leaves, respectively; (a, d) untreated samples; (b, e) HHPE samples (300 MPa for 10 min); (c, f) CE. Adapted from [37] with permission

favorable effects of green tea extracts are attributable to the green tea polyphenolic compounds, mainly catechins. However, a heating treatment during the extraction can decrease the antioxidant activity of green tea due to oxidation, thermal degradation, epimerization, and polymerization of these compounds [48]. Xi and Wang [40] investigated the potential of the HHPE of green tea leaves, aiming to produce extracts containing a higher level of polyphenolics with enhanced antioxidant activity [40]. In comparison with CE, the green tea extract obtained by HPE at $490 \mathrm{MPa}$, at room temperature, and during a shorter time (15-fold less), possessed significantly higher $\alpha$-diphenyl- $\beta$-picrylhydrazyl radical (DPPH) scavenging activity (Table 1 ). Furthermore, Xi et al. [41] studied the effect of HHPE at different pressures (150, 250,350 , and $450 \mathrm{MPa}$ ) on the total phenolics content, extraction yields, and the antioxidant activity of green tea extracts [41]. The results showed that the phenolics and the antioxidant activities of extracts were greatly influenced by high pressure. The total phenolics content and the antioxidant activity of the extract obtained by HPE at $450 \mathrm{MPa}$ was higher than by conventional heat reflux extraction (HRE) (Table 1). In both studies just presented, the higher content of phenolic compounds in the green tea leaves was indicated as the cause for the higher antioxidant activity of the extracts. Thus, it has been concluded that HHPE can be a tool to improve the antioxidant activity of green tea extract.
However, the increased antioxidant activity is not necessarily due only to the high total phenolic content in the extract. For instance, for a green tea extract with a high amount of phenolics with antioxidant properties, $78 \%$ of the antioxidant activity of the extracts was attributed to the particular presence of individual phenolics of the extracts, such as catechins and catechin gallate esters $[48,49]$.

\section{Extract of Propolis and Litchi Fruit Pericarp}

Propolis, the natural resinous substance produced by honeybees from various plant sources, is considered a good source of natural antioxidants such as aromatic acids, phenolic compounds, especially flavonoids (flavones, flavonols, and flavonones), and phenolic acids [50]. HHPE enhanced the antioxidant activity of an ethanolic extract of propolis, with only $1 \mathrm{~min}$ of extraction time (Table 2). The CE methods like HRE and leaching at room temperature (LRT) were applied during 240 and 10,080 min compared with only $1 \mathrm{~min}$ for HHPE, respectively. Even so, the antioxidant activity of the ethanolic extract of propolis obtained by HHPE (86.6\%) was very similar to the results obtained for the tert-butylhydroquinone (87.6\%), a synthetic antioxidant compound commonly used in processed foods. The higher in vitro antioxidant activity of this extract was correlated with higher total 


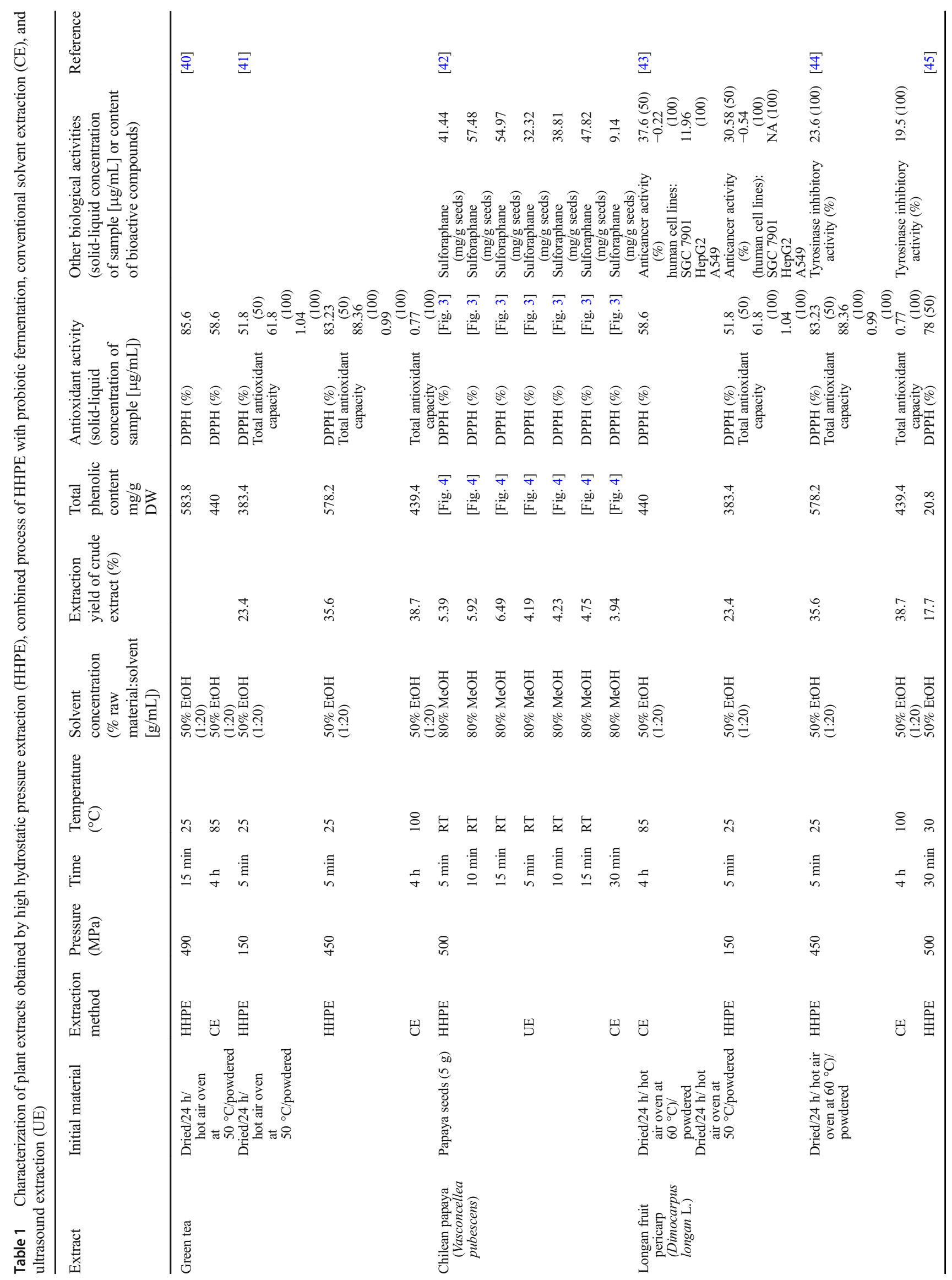




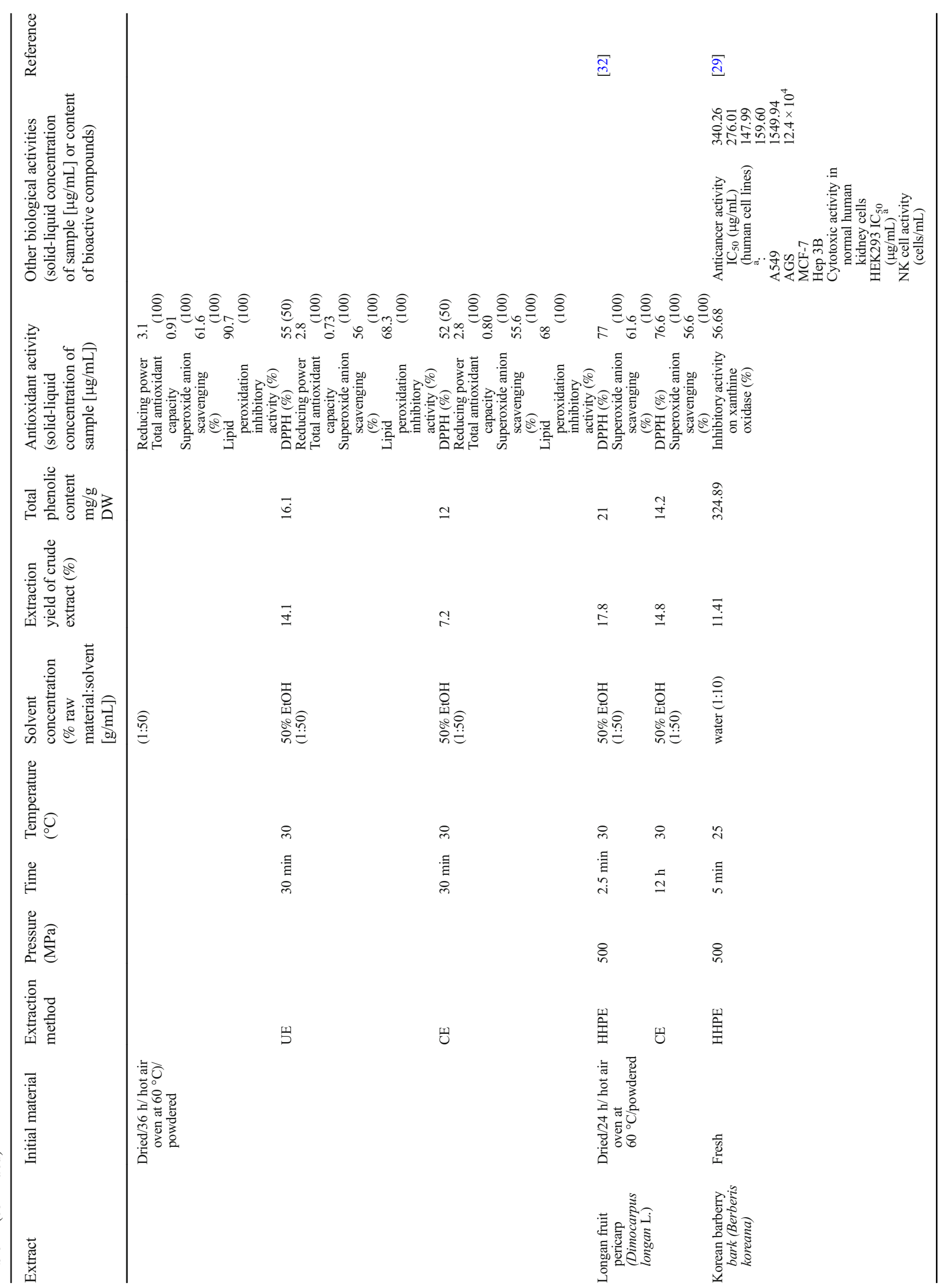




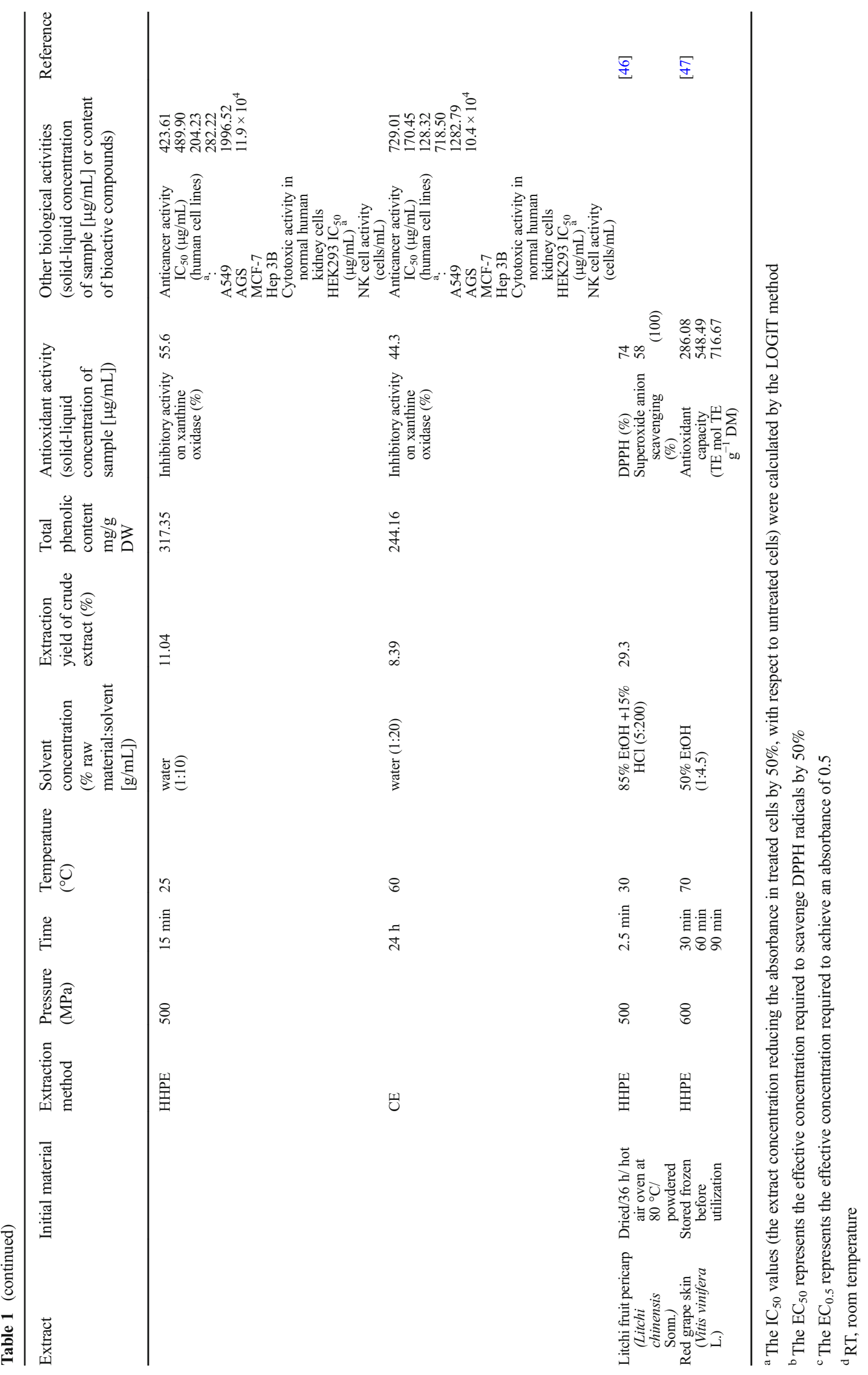


polyphenolics and flavonoids contents. The ethanolic extract of propolis obtained by HHPE provided higher total flavones, flavonols, flavanones, and dihydroflavonols contents, in comparison to HRE (Table 2). Interestingly, HRE resulted in a similar extraction yield of total polyphenols $(6.51 \%)$ compared to HHPE (6.43\%), but the total content of polyphenols was significantly lower in HRE samples. It has been reported that the high ethanol concentration $[95 \%(v / v)]$ used in HRE, results in the extraction of larger amounts of non-polar components and in the decrease of total polyphenols and flavonoids contents [51].

Similarly, Prasad et al. [52] reported a higher extractability of flavonoids from litchi fruit pericarp (Litchi chinensis Sonn.) by HHPE [52]. HHPE enhanced the flavonoid extraction yield up to 2.6-fold and up to 10fold, in comparison with ultrasonication extraction (UE) and CE, respectively. The major flavonoids identified in the extract of litchi pericarp tissues by HHPE at $200 \mathrm{MPa}$, HHPE at $400 \mathrm{MPa}$ and $\mathrm{CE}$ were epicatechin and epicatechin gallate along with catechin and procyanidin B2 as the minor compounds (Table 3). The increasing pressure correlated with the increasing amount of each compound. HHPE at $400 \mathrm{MPa}$ significantly improved the level of catechin to $0.016 \mathrm{mg} / \mathrm{g}$ DW and consequently provided the highest total content of flavonoids in the extract, fostering the conclusion that HHPE was more effective in the extraction of polyphenols. However, the antioxidant activity and total phenolic content of the extract were comparable among the three extraction methods [52]. In another study by the same author, he reported an increased extraction yield of the litchi fruit pericarp by HHPE $(29.3 \%)$ during only $2.5 \mathrm{~min}$, in comparison with CE (19.9\%) and UE $(23 \%)$, but similarly with no significant difference in total phenolic content and antioxidant activity between these extraction methods. In spite of this, the aspect of the extract obtained by HHPE was clear, while those obtained by CE and UE were cloudy and dark. Aside from the selectivity and increased content of the individual components of the bioactive ingredients involved in the extract, HHPE can influence the overall aspect of the extract, which may lead to the production of a natural extract of higher quality [46].

\section{Schisandra chinensis Extract}

Schisandra chinensis (Turcz.) Baill is used as a medical remedy due to its health-promoting properties, such as antioxidant and anticarcinogenic effects. The main active components associated with the bioactive effects of this plant are mainly lignans, including deoxyschisandrin, $\gamma$ schisandrin, and schisandrin, among others [28]. Liu et

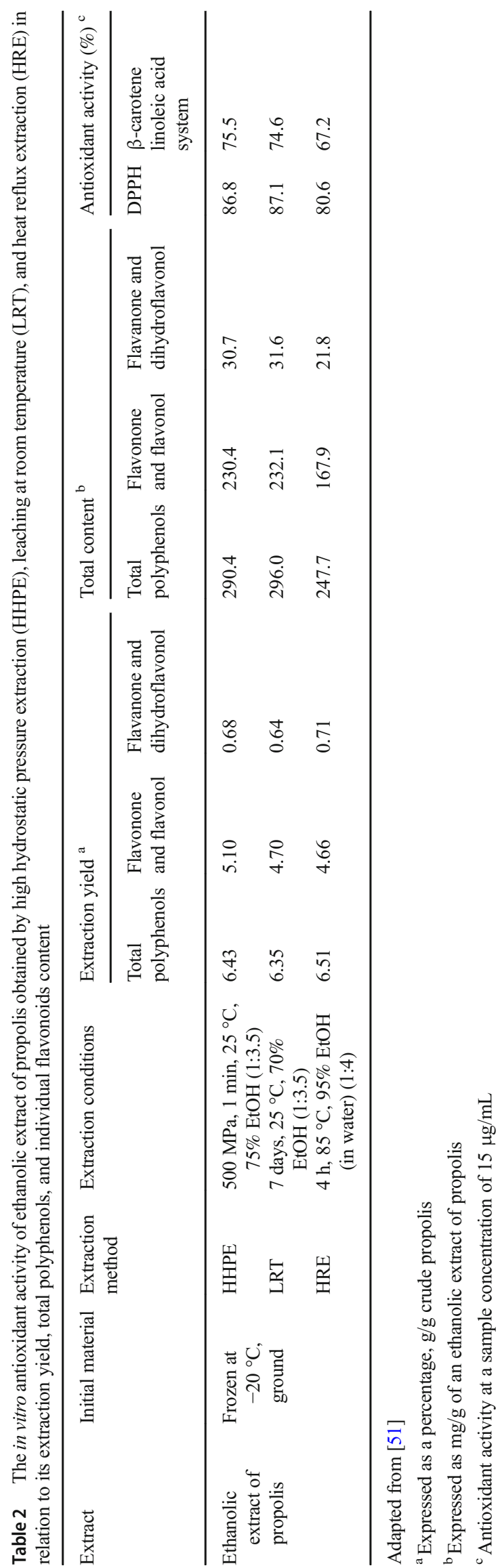


Table 3 Main individual flavonoids in litchi fruit pericarp extract (Litchi chinensis Sonn.) obtained by high hydrostatic pressure extraction (HHPE) at 200 and $400 \mathrm{MPa}$, conventional solvent extraction (CE), and ultrasound extraction (UE)

\begin{tabular}{|c|c|c|c|c|c|c|c|c|}
\hline \multirow[t]{2}{*}{ Extract } & \multirow[t]{2}{*}{ Initial material } & \multirow[t]{2}{*}{ Extraction conditions } & \multirow{2}{*}{$\begin{array}{l}\text { Extraction } \\
\text { method }\end{array}$} & \multicolumn{5}{|c|}{ Individual flavonoids (mg/g DW) } \\
\hline & & & & Epicatechin & $\begin{array}{l}\text { Epicatechin } \\
\text { gallate }\end{array}$ & Catechin & $\begin{array}{l}\text { Procyanidin } \\
\mathrm{B}_{2}\end{array}$ & $\begin{array}{l}\text { Total } \\
\text { content }\end{array}$ \\
\hline \multirow{4}{*}{$\begin{array}{l}\text { Litchi fruit pericarp } \\
\text { (Litchi chinensis } \\
\text { Sonn.) }\end{array}$} & \multirow{4}{*}{$\begin{array}{l}\text { Dried } / 36 \mathrm{~h} / \text { hot air oven } \\
\text { at } 80^{\circ} \mathrm{C} / \text { powdered }\end{array}$} & \multirow{4}{*}{$\begin{array}{r}30 \mathrm{~min}, 25^{\circ} \mathrm{C}, 85 \% \\
\mathrm{EtOH}+1.5 \% \mathrm{HCl}\end{array}$} & HHPE-200 & 0.32 & 0.19 & 0.0016 & 0.14 & 0.6516 \\
\hline & & & HHPE-400 & 0.348 & 0.2527 & 0.0160 & 0.1346 & 0.7513 \\
\hline & & & $\mathrm{CE}$ & 0.0414 & 0.0121 & 0.0002 & 0.0175 & 0.0712 \\
\hline & & & UE & 0.16 & 0.06 & 0.0020 & 0.0731 & 0.2951 \\
\hline
\end{tabular}

Adapted from [52]

al. [16] applied HHPE, HRE and UE extraction to Schisandra chinensis Baill aiming to increase the content of the active components and the antioxidant activity of the plant extract [17]. HHPE extracts possessed the highest antioxidant activity that was associated with the highest extraction yield of deoxyschisandrin and $\gamma$ schisandrin. The optimum extraction conditions were $400 \mathrm{MPa}$ pressure, 90\% ethanol-water solution, 90:1 liquid:solid ratio, and $5 \mathrm{~min}$ extraction time. In fact, the HHPE provided the highest extraction yield of these active compounds within $5 \mathrm{~min}$, which was about 115 and 15 min shorter than HRE and UE, respectively. Thus, besides the advantage of HHPE to improve the antioxidant activity of the Schisandra chinensis extract, this extraction was the most economical extraction method for deoxyschisandrin and $\gamma$-schisandrin. The HHPE of Schisandra chinensis may provide an opportunity in the field of the discovery of new drugs based on lignans that constitute the main secondary metabolites of this plant.

\section{Sargassum muticum Extract}

The brown seaweed Sargassum muticum is rich in bioactive polysaccharides, which has several health benefits associated with it, such as antioxidant activity. Rodrigues et al. [53] evaluated the potential and the effectiveness of HHPE to obtain extracts concentrated in bioactive sulfated polysaccharides from $S$. muticum and tested the antioxidant activity of the extract [53]. The results demonstrated that the extraction yield ranged between 32 and $40.4 \%$ resulting in average increases of 3.6 to 4.8 -fold for total sugars and sulfated sugars, as compared to CE. Extracts displayed improved antioxidant activities, yet maximum values were achieved at $300 \mathrm{MPa}$ for 5$5.5 \mathrm{~min}$ and $1 \mathrm{~g}$ of dry seaweed for yield. HHPE increased extractability and bioactivity from the seaweed $S$. muticum, providing extracts with higher content in polysaccharides, which can be used as ingredients to develop novel functional foods.

\section{Longan Fruit Pericarp and Korean Barberry Extracts}

An extract of longan (Dimocarpus longan L.) fruit pericarp (LFP) has been reported to possess antioxidant, antiinflammatory, anticarcinogenic, and antihyperglycemic activities, mainly due to a great source of high quality phenolic compounds (i.e., gallic acid, and ellagic acid, and corilagin) $[54,55]$. Antioxidant model systems, including DPPH and superoxide anion scavenging [32, 43-45], lipid peroxidation inhibitory activity $[43,45]$, total antioxidant capacity scavenging $[44,45]$, and reducing power [45] were used to determine the antioxidant activity of the LFP extract obtained by HHPE and CE techniques (Table 1). The extract obtained by HHPE, at a pressure of $500 \mathrm{MPa}$, with $50 \%$ ethanol, at $30{ }^{\circ} \mathrm{C}$ for only 2.5 and $30 \mathrm{~min}$, possessed the highest total phenolics content and antioxidant activity in comparison with CE, and UE methods (Table 1). The antioxidant activities correlated positively with the total content of phenolics present in the extracts. However, these results fail to report on the identities and content of the individual phenolics involved in the extracts obtained by HHPE and other methods. Nevertheless, a relationship between the intake of polyphenols and reduced risk of certain cancers has been found. The alteration of tyrosinase (EC 1.14.18.1), an enzyme involved in the production of melanin, has been referred as responsible for a part of the histopathological features which are unique to malignant melanoma. Its inhibition activity might be dependent on the hydroxyl group of the phenolic compounds that can form a hydrogen bond to a site of the enzyme, leading to lower enzymatic activity. The extract of LFP obtained by HHPE showed superior results indicating an almost 2-fold increase of total phenolics content and consequently higher tyrosinase inhibitory activity, compared to $\mathrm{CE}$ (Table 1) [44]. Three polyphenolic compounds, namely, gallic acid, ellagic acid, and corilagin were identified as the major phenolic acids in the LFP extract. The content of individual phenolics varied with increasing pressure (Table 4) [44]. The extract obtained by HHPE at $500 \mathrm{MPa}$ contained an almost 2fold higher amount of total phenolic acids $(10.5 \mathrm{mg} / \mathrm{g} \mathrm{DW})$ when compared to those obtained by CE $(5.4 \mathrm{mg} / \mathrm{g} \mathrm{DW})$. 
HHPE extracts possessed excellent selectivity for corilagin in the LFP extract. According to the content of individual phenolic acids after HHPE, the corilagin content was $9.6 \mathrm{mg} / \mathrm{g}$ DW at $500 \mathrm{MPa}$, which was higher than the $2.3 \mathrm{mg} / \mathrm{g}$ DW obtained by $\mathrm{CE}$ (ethanol extraction using $50 \%$ ethanol for $30 \mathrm{~min}$ at $30^{\circ} \mathrm{C}$ ) (Table 4) [44]. In another study by this author, the corilagin content in LFP extract obtained by HHPE (at $500 \mathrm{MPa}$ ) was higher in comparison to the one obtained by UE and about 4fold more in comparison to the extract obtained by CE (Table 4) [45]. This compound has been recognized as a potent antitumor herbal medicine, since it has been successfully applied for the inhibition of ovarian cancer cell growth [56]. The extracts of LFP by HHPE and CE were tested against some cancer cell lines. It has been found that the LFP extract obtained by HHPE was more effective to inhibit human cancer cell lines, like human gastric cancer cell lines (SGC-7901), and human lung carcinoma (A549), compared to $\mathrm{CE}$ (with ethanol), and even higher for SGC-7901 in comparison to Cisplatin, a commercial chemotherapy drug (Table 1) [43]. Likewise, the extract of the Korean barberry (Berberis koreana) obtained by HHPE at $500 \mathrm{MPa}$ for 5 min (HHPE-5) demonstrated an enhanced in vitro inhibitory activity on the human cell lines, like A549 and human hepatocellular carcinoma (Hep3B) than the $\mathrm{CE}$ (Table 1). Moreover, this extract showed a higher exhibition effect on natural killer (NK) cell growth, compared to HPE at $500 \mathrm{MPa}$ for $15 \mathrm{~min}$, and CE. Generally, the NK cells have cytolytic activity against several tumors and it has been found that some bioactive compounds of plant origin can modulate the activity of the NK, which can be exploited for cancer prevention and treatment [57]. In both studies just presented, HHPE increased the anticancer activity of the extracts. The more efficient anticancer activity was verified in the extracts with the higher phenolic content. However, different and possibly useful compounds could be extracted using the HHPE rather than $\mathrm{CE}$, which could contribute to the higher bioactivity of the extracts. Therefore, further investigation of the identification and effects of individual components is necessary to improve the extraction efficiency of HHPE.

\section{Papaya Seeds and Fig Extracts}

Papaya seeds are discarded after the fruit has been consumed, but they contain many bioactive compounds such as polyphenols, carotenoids and vitamin C. Moreover, some of these phytochemicals protect major biomolecules from oxidation caused by free radicals, thus preventing the onset of many chronic diseases, such as cancer, diabetes, and obesity. Exclusively, papaya is a unique fruit in the Caricaceae family, containing sulforaphane (SFN), belonging to the family of isothiocyanates [58]. The SFN is a compound considered to be an important and active substance for reducing the risk of cancer [59]. Briones-Labarca et al. [42] applied HHPE, UE, and CE to papaya by-products like papaya seeds, aiming to study their effect on the bioactive compounds. The results showed that HHPE was more effective than UE and CE methods as the former led to a higher extraction yield of SFN in a much shorter extraction time. The content of SFN in the papaya seed extract increased significantly in 353.4, 528.9 and $501.4 \%$ for HHPE at $500 \mathrm{MPa}$ for 5,10 and 15 min, respectively, and 253.6, 324.6, and $423.2 \%$ for UE by 5,10 and $15 \mathrm{~min}$, respectively, relative to $\mathrm{CE}$ (agitation for $1 \mathrm{~h})$. Moreover, the extract obtained by HHPE showed the highest antioxidant capacity, total phenolic content, and flavonoid content (Figs. 3 and 4). The phenolic compounds and flavonoids have been suggested as being the primary contributors to the antioxidant activity of papaya seed extract. However, their individual identification has not been investigated yet. Nevertheless, these findings raise the possibility that HHPE can produce natural extracts enriched with bioactive compounds (i.e., the natural anticancer compound SFN), which can have potential application in the pharmaceutical industry.

Similarly, Alexandre et al. [60] applied HHPE to obtain fig by-product derived extracts and its impact was evaluated as to antioxidant activity and total phenolic, tannin, and flavonoid compounds [60]. HHPE led to an increase of $8-13 \%$ of antioxidant activity and an increase of $8-11 \%$ of total phenolic, flavonoid, and tannin contents when compared to extracts

Table 4 The main individual phenolic acids identified in Longan fruit pericarp (Dimocarpus longan Lour.) extract using different high hydrostatic pressure extractions (HHPE-200, HHPE-300, HHPE 400, and HHPE-500 MPa), conventional solvent extraction (CE), and ultrasound extraction (UE)

\begin{tabular}{|c|c|c|c|c|c|c|c|}
\hline \multirow[t]{2}{*}{ Extract } & \multirow[t]{2}{*}{ Initial material } & \multirow[t]{2}{*}{ Extraction method } & \multicolumn{4}{|c|}{ Individual phenolic acids (mg/g DW) } & \multirow[t]{2}{*}{ Reference } \\
\hline & & & Gallic acid & Ellagic acid & Corilagin & Total content & \\
\hline \multirow{8}{*}{$\begin{array}{l}\text { Longan fruit pericarp } \\
\text { (Dimocarpus longan Lour.) }\end{array}$} & \multirow{5}{*}{$\begin{array}{l}\text { Dried } / 24 \mathrm{~h} / \text { hot air oven } \\
\text { at } 60^{\circ} \mathrm{C} \text { )/ powdered }\end{array}$} & HHPE-200 & 0.1 & 0.8 & 5.9 & 6.8 & \multirow[t]{5}{*}{ [44] } \\
\hline & & HHPE-300 & 0.7 & 0.9 & 7.2 & 8.8 & \\
\hline & & HHPE-400 & 0.08 & 0.9 & 8.2 & 9.1 & \\
\hline & & HHPE-500 & 0.01 & 0.9 & 9.6 & 10.5 & \\
\hline & & $\mathrm{CE}$ & 2.2 & 0.9 & 2.3 & 5.4 & \\
\hline & \multirow{3}{*}{$\begin{array}{l}\text { Dried } / 36 \mathrm{~h} / \text { hot air oven } \\
\text { at } 60^{\circ} \mathrm{C} \text { )/ powdered }\end{array}$} & HHPE-500 & 0.0140 & 0.926 & 9.65 & 10.59 & \multirow[t]{3}{*}[45]{} \\
\hline & & $\mathrm{CE}$ & 2.25 & 0.977 & 2.37 & 5.597 & \\
\hline & & UE & 0.0125 & 0.0 .345 & 7.91 & 8.2675 & \\
\hline
\end{tabular}


Fig. 3 Antioxidant capacity as DPPH ( $\mu$ mol TE $\mathrm{g}^{-1}$ seeds) from Chilean papaya seeds extracted by $\mathrm{CE}$ (conventional extraction), UE (ultrasound extraction), and HHPE (high hydrostatic pressure extraction). Different letters above the bars indicate significant differences between mean values $(p \leq 0.05)$. Adapted from [42] with permission

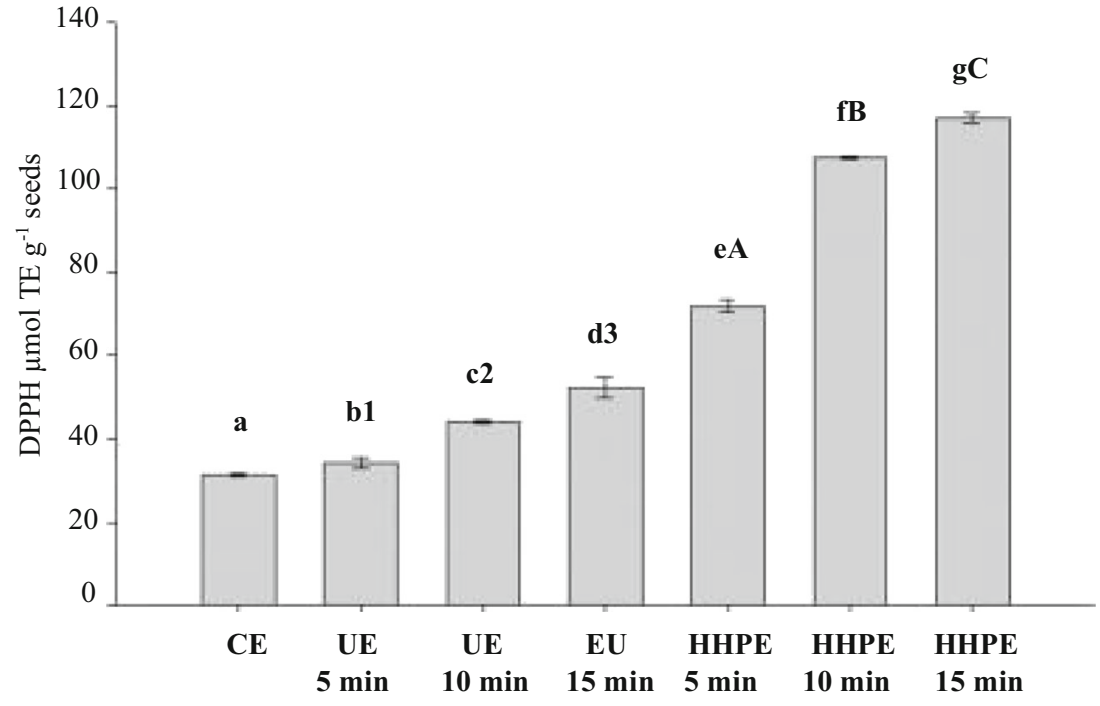

performed at $0.1 \mathrm{MPa}$. The amount of almost all bioactive compounds extracted from processing fig by-product can be increased using high pressure together with an optimized ethanol concentration and extraction time. Moreover, independently of ethanol concentration and extraction time, HHPE resulted always in improved extraction, up to a maximum of $35 \%$ for total flavonoids at $600 \mathrm{MPa}, 40 \%$ ethanol, and $30 \mathrm{~min}$ of extraction time. The exploitation of high pressure for extracting bioactive compounds from an industrial fig by-product for their application in food and pharmaceutics is a promising field.

\section{Korean Ginseng Roots and Opuntia Cactus Extracts}

Ginsenosides are the principal bioactive components present in ginseng and are responsible for several pharmacological activities, such as immunosuppressive, antiinflammatory, immunological adjuvant, anticarcinogenic, and woundhealing activities. In extraction, enzymes can be used for transformation of the major ginsenosides into more pharmacologically active minor ginsenosides. However, currently available enzyme preparations cannot completely hydrolyze plant cell walls, thus limiting the extraction yields of these compounds [61]. Palaniyandi et al. [62] investigated a combination of HHPE and various enzyme combinations to obtain extracts of Korean ginseng roots (Panax ginseng C.A. Meyer) with enhanced levels of specific minor ginsenosides, like the Rg1 and Rb1 [62]. The use of enzymes like cellulase+amylase+pectinase (enzymes concentration, $0.5+2+2 \mathrm{U} / \mathrm{mL}$, respectively) with combination of HHPE at $100 \mathrm{MPa}$ allowed for the efficient extraction of ginsenosides $\mathrm{Rg} 1$ and $\mathrm{Rb} 1$ from fresh ginseng roots (under optimized temperature, $\mathrm{pH}$, and processing time, like $45^{\circ} \mathrm{C}, \mathrm{pH} 4.8$, and $12 \mathrm{~h}$, respectively). The treatment with enzymes and HHPE could destroy the cell wall and enhance the extraction of bioactive metabolites from
Fig. 4 Comparison of total phenolic content from Chilean papaya seeds extracted by $\mathrm{CE}$ (conventional extraction), UE (ultrasound extraction), and HHPE (high hydrostatic pressure extraction). Different letters above the bars indicate significant differences between mean values $(p \leq 0.05)$. Adapted from [42] with permission

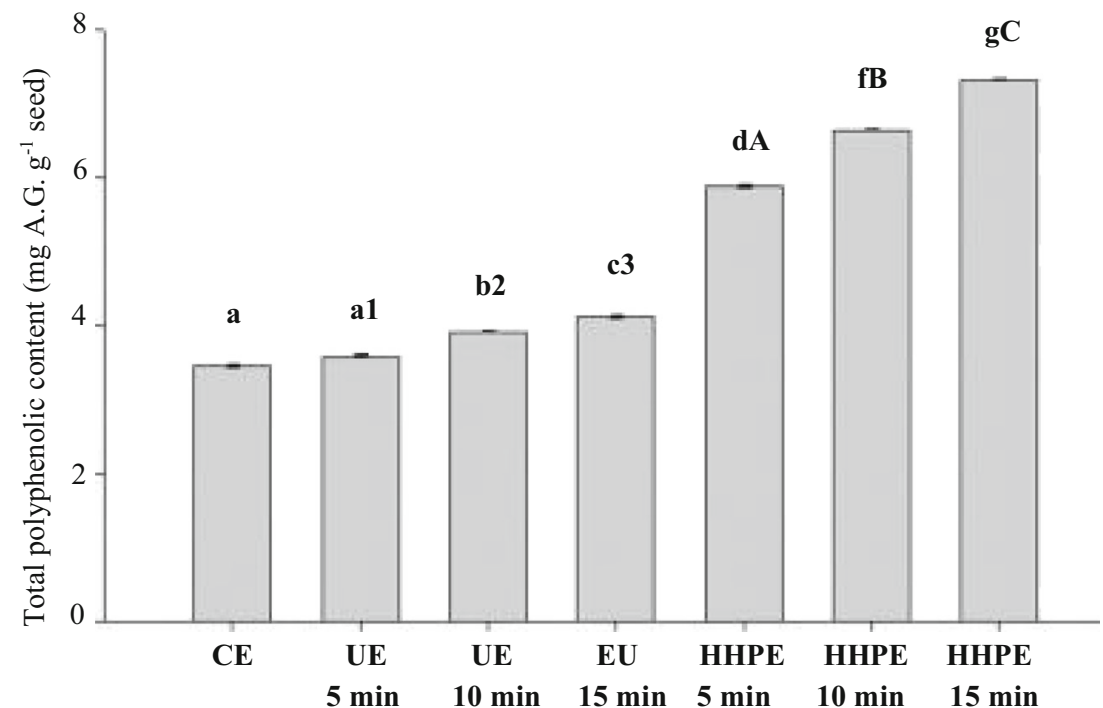


ginseng tissue. Indeed, the stability and activity of most enzymes are not altered at pressures lower than $100 \mathrm{MPa}$ [19].

Moreover, an enhanced extraction of bioactive components from Opuntia cactus (Opuntia humifusa) was observed in the combination of HHPE with enzymes in comparison with HHPE only, enzyme only treatment under atmospheric pressure, and CE. The cactus homogenate in water treated with polysaccharide-degrading enzymes (Rapidase-Viscozyme mixture) under high pressure selectively increased the amount of the active components (i.e., taxifolin, quercetin, and isorhamnetin) (Table 5) and enhanced the radical scavenging activity against ABTS and DPPH radicals [63]. In both studies presented above, HHPE with enzyme combination could provide a cheap and eco-friendly method for preparing the natural extracts enriched with pharmacologically active compounds.

\section{Enhanced Antibacterial and Antimutagenic Activity of Plant Extracts by HHPE}

Fermentation using live, safe, and non-pathogenic probiotic stains has been suggested as a process that can improve functional and biological properties such as antioxidant and antimicrobial activities of natural extracts, through a microbial conversion of some bioactive compounds and the production of secondary metabolites [64].

The potential application of the combined process of HHPE with probiotic fermentation was investigated as a technique for the enhancement of biological activities of Korean barberry (Berberis koreana) [65] and deodeok (Codonopsis lanceolata) extracts [66].

Samples of deodeok were anaerobically fermented with Lactobacillus acidophilus ADH (LAF-HHPE), Bifidobacterium longum B6 (BLF-HHPE), Lactobacillus rhamnosus GG (LRFHHPE), and Lactobacillus paracasei (LPF-HHPE) at $37^{\circ} \mathrm{C}$ for 10 days and subjected afterwards to $500 \mathrm{MPa}$ at $50{ }^{\circ} \mathrm{C}$ for
30 min. Differently, the Korean barberry samples were first subjected to high pressure at $500 \mathrm{MPa}$ for $30 \mathrm{~min}$ and then the extracts were fermented with Bifidobacterium longum B6 (HHPE-BLF) and Lactobacillus paracasei (HHPE-LPF) at $37^{\circ} \mathrm{C}$ for six days.

The Korean barberry and deodeok extracts obtained by HHPE without fermentation (HHPE-NF) showed the highest total phenolics content and antioxidant activity (deodeok extract), in comparison to those obtained by CE non-fermented extraction (CE-NF) and probiotic fermentation in combination with HHPE.

In the HHPE-NF Korean barberry extract, the highest amounts of phenolic acids were observed, with $p$ hydroxybenzoic acid being predominant, followed by vanillic acid, vanillin, and $p$-hydroxybenzaldehyde. These compounds were reduced in the combined HHPE-fermented extracts, probably because the phenolic acids could be further decarboxylated by microbial enzymes produced during the probiotic fermentation. Comparable results were found in all deodeok extracts obtained by HHPE (fermented or not fermented), indicating that the HHPE efficiently extracts and recovers phenolic acids, especially the hydroxybenzoic acids.

In spite of this, the HHPE-fermented extracts of both the Korean barberry and the deodeok showed better antibacterial and mutagenic activities, in comparison to only HHPE and CE. Korean barberry showed significantly higher antibacterial activity against a $\beta$-lactam resistant Staphylococcus aureus and a $\beta$-lactam sensitive Staphylococcus aureus, as well as antimutagenic activity when compared to CE-NF and HHPE-NF [65]. Similarly, the fermented-HHPE extracts of deodeok exhibited the highest antimutagenic activities against TA 100, TA 1537 and TA 98 mutants of Salmonella typhimurium and a significant antibacterial activity against Listeria monocytogenes, $S$. aureus, Shigella boydii and $S$. typhimurium [66], possibly due to the production of specific secondary metabolites produced during the fermentation

Table 5 The main individual flavonols identified in Opuntia cactus (Opuntia humifusa) extract using heat extraction, high hydrostatic pressure extractions (HHPE) at 100, 200 and $300 \mathrm{MPa}$, enzyme-assisted extraction (EAE), and the combination of HHPE and EAE (HHPE-EAE)

\begin{tabular}{|c|c|c|c|c|c|c|c|}
\hline \multirow[t]{2}{*}{ Extract } & \multirow[t]{2}{*}{ Initial material } & \multirow[t]{2}{*}{ Extraction method } & \multirow[t]{2}{*}{ Extraction conditions } & \multicolumn{4}{|c|}{ Flavonols $(\mu \mathrm{g} / \mathrm{mL})$} \\
\hline & & & & Quercitrin & Taxifolin & Quercetin & Isorhamnetin \\
\hline \multirow[t]{8}{*}{$\begin{array}{l}\text { Opuntia cactus } \\
\qquad(\text { Opuntia humifusa })\end{array}$} & \multirow[t]{8}{*}{ Fresh samples } & $\begin{array}{l}\text { Heat } \\
\text { Extraction }\end{array}$ & Water bath, $2 \mathrm{~h}, 95^{\circ} \mathrm{C}$ & 54.21 & 97.67 & 18.43 & 15.36 \\
\hline & & HHPE-100 & Homogenate & 55.08 & 94.62 & 19.34 & 14.21 \\
\hline & & HHPE-200 & in water, $1 \mathrm{~h}, 40^{\circ} \mathrm{C}$ & 50.73 & 96.37 & 20.10 & 13.89 \\
\hline & & HHPE-300 & & 51.67 & 96.66 & 17.88 & 14.05 \\
\hline & & EAE & $\begin{array}{l}\text { [Rapidase-Viscozyme mixture, } \\
1 / 3(\mathrm{v} / \mathrm{v})]\end{array}$ & 21.87 & 163.79 & 43.27 & 23.32 \\
\hline & & HHPE-EAE-100 & Homogenate in water & 23.45 & 179.21 & 47.21 & 32.12 \\
\hline & & HHPE-EAE-200 & + [Rapidase-Viscozyme mixture & 20.26 & 181.96 & 50.34 & 30.27 \\
\hline & & HHPE-EAE-300 & $1 / 3(\mathrm{v} / \mathrm{v})] / 1 \mathrm{~h}, 40^{\circ} \mathrm{C}$ & 18.90 & 188.33 & 52.43 & 34.12 \\
\hline
\end{tabular}

Adapted from [63] 
process. The combination of fermentation and HHPE may improve the antimicrobial and antimutagenic effectiveness of the referred extracts. However, more studies are needed to elucidate the mechanism of microbial conversion of the extracts and to identify bioactive metabolites produced during the HHPE and fermentation process.

\section{Conclusion}

The application of HHPE to natural materials shows several advantages when compared to the traditional extraction methods. HHPE operates at room or reduced temperature, which can protect the natural extracts from heat influence and thus improve their bioactivity. Under high pressure, the differential pressure between the interior and the exterior of cell membranes is so large, that it can lead to rapid permeation and a faster equilibrium of concentration between the cell interior and its exterior, while increased solubility can also occur for several compounds. Moreover, at shorter extraction times, the natural plant extracts possessed higher antioxidant, and anticarcinogenic activities, which proportionally correlated with the higher total phenolic content. Furthermore, HHPE of plant materials can selectively increase the main individual bioactive compounds of great importance in the extract, such as corilagin and the sulforaphane, which have been considered to be effective antitumor compounds. The use of HHPE in order to obtain bioactive compounds from raw materials is a very promising recent extraction technique for the extraction of bioactive compounds from natural materials and improving the bioactivity of natural extracts associated with better nutritional benefits and therapeutic potential. The natural extracts obtained by HHPE can provide a source of antioxidant phenolic compounds for the food and pharmaceutical industries, to replace artificial chemical antioxidants as well as to enhance the bioactivity of biomolecules.

However, while the effect of pressure on the total phenolic content and biological activities of the extracts has been researched, there is still a lack of experimental data for most bioactive compounds (e.g., individual phenolics) responsible for the enhanced biological activities of the HHPE natural extracts. Further studies are needed to identify these compounds and assess the way in which they contribute to these activities. In addition, more research is needed to demonstrate the bioactivity of HHPE extracts with in vivo studies, to confirm their bioavailability and potential health benefits. Since the research in the field of HHPE is taking its first steps, deeper studies are needed to ascertain the full potential of HHPE.

Acknowledgments The authors are grateful to the Foundation for Science and Technology (FCT) of Portugal for the $\mathrm{PhD}$ grants attributed to H. Scepankova (SFRH/BD/88133/2012) and M. Martins (SFRH/BD/ 122220/2016) and to FCT/MEC for the financial support to the QOPNA research Unit (FCT UID/QUI/00062/2013), through national funds and where applicable co-financed by the FEDER, within the PT2020 Partnership Agreement.

\section{Compliance with Ethical Standards}

Permission to used material already published was carried out and granted.

Conflict of Interest The authors declare that they have no conflict of interest.

\section{References}

1. Pham-Huy LA, He H, Pham-Huy C (2008) Free radicals, antioxidants in disease and health. Int J Biomed Sci 4:89-96 https://www. ncbi.nlm.nih.gov/pmc/articles/PMC3614697/

2. Premanath R, Lakshmidevi N (2010) Studies on anti-oxidant activity of Tinospora cordifolia (Miers.) leaves using in vitro models. J Am Sci 6:736-743

3. Kennedy DO, Wightman EL (2011) Herbal extracts and phytochemicals: plant secondary metabolites and the enhancement of human brain function. Adv Nutr 2:32-50. https://doi.org/10.3945/ an.110.000117.32

4. Dany M, Madi N, Nemer N, Beyrouthy M, Abdoun S, Usta J (2012) Moringa oleifera: natural leaf extract with potential anticancerous effect on A549 lung cancel cells. Lung Cancer 77:521527. https://doi.org/10.1016/j.lungcan.2012.05.035

5. Djeridane A, Hamdi A, Bensania W, Cheifa K, Lakhdari I, Yousfi $M(2015)$ The in vitro evaluation of antioxidant activity, $\alpha$ glucosidase and $\alpha$-amylase enzyme inhibitory of natural phenolic extracts. Diabetes Metab Syndr Clin Res Rev 9:324-331. https:// doi.org/10.1016/j.dsx.2013.10.007

6. Gambari R (2011) Predictive analyses of biological effects of natural products: from plant extracts to biomolecular laboratory and computer modeling properties relevant for alternative treatments of human diseases. Evid Based Complement Alternat Med 2011:1-4. https://doi.org/10.1093/ecam/nep096

7. Dai J, Mumper RJ (2010) Plant phenolics: extraction, analysis and their antioxidant and anticancer properties. Molecules 15:73137352. https://doi.org/10.3390/molecules 15107313

8. Zheng W, Wang SY (2001) Antioxidant activity and phenolic compounds in selected herbs. J Agric Food Chem 49:5165-5170. https://doi.org/10.1021/jf010697n

9. Kähkönen MP, Hopia A, Vuorela HJ et al (1999) Antioxidant activity of plant extracts containing phenolic compounds. J Agric Food Chem 47:3954-3962. https://doi.org/10.1021/jf9901461

10. Wang S, Marcone MF, Barbut S, Lim L (2012) Fortification of dietary biopolymers-based packaging material with bioactive plant extracts. Food Res Int 49:80-91. https://doi.org/10.1016/j.foodres. 2012.07.023

11. Piluzza G, Bullitta S (2011) Correlations between phenolic content and antioxidant properties in twenty-four plant species of traditional ethnoveterinary use in the Mediterranean area. Pharm Biol 49:240 247. https://doi.org/10.3109/13880209.2010.501083

12. Nuutila AM, Puupponen-Pimia R, Aarni M, Oksman-Caldentey KM (2003) Comparison of antioxidant activities of onion and garlic extracts by inhibition of lipid peroxidation and radical scavenging activity. Food Chem 81:485-493. https://doi.org/10.1016/S03088146(02)00476-4

13. Ismail T, Sestili P, Akhtar S (2012) Pomegranate peel and fruit extracts: a review of potential anti-inflammatory and anti-infective 
effects. J Ethnopharmacol 143:397-405. https://doi.org/10.1016/j. jep.2012.07.004

14. Guimarães R, Barros L, Calhelha RC, Carvalho AM, Queiroz MJRP, Ferreira ICFR (2014) Bioactivity of different enriched phenolic extracts of wild fruits from northeastern Portugal: a comparative study. Plant Foods Hum Nutr 69:37-42. https://doi.org/10. 1007/s11130-013-0394-5

15. Veggi PC, Cavalcanti RN, Meireles MA (2014) Production of phenolic-rich extracts from Brazilian plants using supercritical and subcritical fluid extraction: experimental data and economic evaluation. J Food Eng 131:96-109. https://doi.org/10.1016/j. jfoodeng.2014.01.027

16. Spigno G, Tramelli L, De Faveri DM (2007) Effects of extraction time, temperature and solvent on concentration and antioxidant activity of grape marc phenolics. J Food Eng 81:200-208. https://doi. org/10.1016/j.jfoodeng.2006.10.021

17. Liu C, Zhang S, Wu H (2009) Non-thermal extraction of effective ingredients from Schisandra chinensis Baill and the antioxidant activity of its extract. Nat Prod Res 23:1390-1401. https://doi.org/ 10.1080/14786410902726100

18. Borhan MZ, Ahmad R, Rusop M, Abdullah S (2013) Green extraction: enhanced extraction yield of asiatic acid from Centella asiatica (L.) nanopowders. J Appl Chem 2013:1-7. https://doi. org $/ 10.1155 / 2013 / 460168$

19. Lee HS, Lee HJ, Yu HJ, Ju DW, Kim Y, Kim CT, Kim CJ, Cho YJ, Kim N, Choi SY, Suh HJ (2011) A comparison between high hydrostatic pressure extraction and heat extraction of ginsenosides from ginseng (Panax ginseng CA Meyer). J Sci Food Agric 91: 1466-1473. https://doi.org/10.1002/jsfa.4334

20. Dorta E, Lobo MG, González M (2013) Improving the efficiency of antioxidant extraction from mango peel by using microwaveassisted extraction. Plant Foods Hum Nutr 68:190-199. https:// doi.org/10.1007/s11130-013-0350-4

21. Yan L, Xi J (2017) Micro-mechanism analysis of ultrahigh pressure extraction from green tea leaves by numerical simulation. Sep Purif Technol 180:51-57. https://doi.org/10.1016/j.seppur.2017.02.041

22. Gil-Chávez GJ, Villa JA, Ayala-Zavala FJ et al (2013) Technologies for extraction and production of bioactive compounds to be used as nutraceuticals and food ingredients: an overview. Compr Rev Food Sci Food Saf 12:5-23. https://doi.org/10.1111/1541-4337.12005

23. Sousa SG, Delgadillo I, Saraiva J (2014) Effect of thermal pasteurisation and high-pressure processing on immunoglobulin content and lysozyme and lactoperoxidase activity in human colostrum. Food Chem 151:79-85. https://doi.org/10.1016/j.foodchem. 2013.11.024

24. Roldán-Marín E, Sánchez-Moreno C, Lloría R, de Ancos B, Cano MP (2009) Onion high-pressure processing: flavonol content and antioxidant activity. LWT-Food Sci Technol 42:835-841. https:// doi.org/10.1016/j.lwt.2008.11.013

25. Jun X (2013) High-pressure processing as emergent technology for the extraction of bioactive ingredients from plant materials. Crit Rev Food Sci Nutr 53:837-852. https://doi.org/10.1080/ 10408398.2011.561380

26. Briones-Labarca V, Giovagnoli-Vicuña $C$, Figueroa-Alvarez $P$, Quispe-Fuentes I, Pérez-Won M (2013) Extraction of $\beta$-carotene, vitamin $\mathrm{C}$ and antioxidant compounds from Physalis peruviana (Cape Gooseberry) assisted by high hydrostatic pressure. Food Nutr Sci 4:109-118. https://doi.org/10.4236/fns.2013.48A014

27. Huang HW, Hsu CP, Yang BB, Wang C (2013) Advances in the extraction of natural ingredients by high pressure extraction technology. Trends Food Sci Technol 33:54-62. https://doi.org/10. 1016/j.tifs.2013.07.001

28. Huang W-Y, Cai Y-Z, Zhang Y (2010) Natural phenolic compounds from medicinal herbs and dietary plants: potential use for cancer prevention. Nutr Cancer 62:1-20. https://doi.org/10.1080/ 01635580903191585
29. Qadir SA, Kwon MC, Han JG, Ha JH, Chung HS, Ahn J, Lee HY (2009) Effect of different extraction protocols on anticancer and antioxidant activities of Berberis koreana bark extracts. J Biosci Bioeng 107:331-338. https://doi.org/10.1016/j.jbiosc.2008.11.021

30. Mota M, Lopes R, Delgadillo I, Saraiva J (2013) Microorganisms under high pressure - adaptation, growth and biotechnological potential. Biotechnol Adv 31:1426-1434. https://doi.org/10.1016/j. biotechadv.2013.06.007

31. Balasubramaniam VMB, Martinez-Monteagudo S, Gupta R (2015) Principles and application of high pressure-based technologies in the food industry. Food Sci Technol 6:435-462. https://doi.org/10. 1146/annurev-food-022814-015539

32. Prasad KN, Yang B, Zhao M, Wei X, Jiang Y, Chen F (2009) High pressure extraction of corilagin from longan (Dimocarpus longan Lour.) fruit pericarp. Sep Purif Technol 70:41-45. https://doi.org/ 10.1016/j.seppur.2009.08.009

33. Santos MC, Salvador ÂC, Domingues FM, Cruz JM, Saraiva JA (2012) Use of high hydrostatic pressure to increase the content of xanthohumol in beer wort. Food Bioprocess Technol 6:2478-2485. https://doi.org/10.1007/s11947-012-0952-0

34. Kadam P, Jadhav B, Salve R, Machewad G (2011) Review on the high pressure technology (HPT) for food preservation. J Food Process Technol 3:1-5. https://doi.org/10.4172/2157-7110. 1000135

35. Stiles TK (2010) The effects of high pressure processing on peanut sauce inoculated with Salmonella. Dissertation \& Theses in Food Science and Technology - University of Nebraska-Lincoln

36. Jun X, Deji S, Ye L, Rui Z (2011) Micromechanism of ultrahigh pressure extraction of active ingredients from green tea leaves. Food Control 22:1473-1476. https://doi.org/10.1016/j.foodcont. 2011.03.008

37. Xi J, Luo S (2016) The mechanism for enhancing extraction of ferulic acid from Radix Angelica sinensis by high hydrostatic pressure. Sep Purif Technol 165:208-213. https://doi.org/10.1016/j. seppur.2016.04.011

38. Pinela J, Prieto MA, Barros L, Carvalho AM, Oliveira MBPP Saraiva JA, Ferreira ICFR (2017) Cold extraction of phenolic compounds from watercress by high hydrostatic pressure: process modelling and optimization. Sep Purif Technol 192:501-512. https://doi.org/10.1016/j.seppur.2017.10.007

39. Corrales M, Toepfl S, Butz P, Knorr D, Tauscher B (2008) Extraction of anthocyanins from grape by-products assisted by ultrasonics, high hydrostatic pressure or pulsed electric fields: a comparison. Innov Food Sci Emerg Technol 9:85-91. https://doi.org/ 10.1016/j.ifset.2007.06.002

40. Xi J, Wang B (2013) Optimization of ultrahigh-pressure extraction of polyphenolic antioxidants from green tea by response surface methodology. Food Bioprocess Technol 6:2538-2546. https://doi. org/10.1007/s11947-012-0891-9

41. Xi J, Shen D, Li Y, Zhang R (2011) Ultrahigh pressure extraction as a tool to improve the antioxidant activities of green tea extracts. Food Res Int 44:2783-2787. https://doi.org/10.1016/j.foodres. 2011.06.001

42. Briones-Labarca V, Plaza-Morales M, Giovagnoli-Vicuña C, Jamett F (2015) High hydrostatic pressure and ultrasound extractions of antioxidant compounds, sulforaphane and fatty acids from Chilean papaya (Vasconcellea pubescens) seeds: effects of extraction conditions and methods. LWT-Food Sci Technol 60:525-534. https:// doi.org/10.1016/j.lwt.2014.07.057

43. Prasad NK, Hao J, Shi J et al (2009) Antioxidant and anticancer activities of high pressure-assisted extract of longan (Dimocarpus longan Lour.) fruit pericarp. Innov Food Sci Emerg Technol 10: 413-419. https://doi.org/10.1016/j.ifset.2009.04.003

44. Prasad KN, Yang B, Shi J, Yu C, Zhao M, Xue S, Jiang Y (2010) Enhanced antioxidant and antityrosinase activities of longan fruit 
pericarp by ultra-high-pressure-assisted extraction. J Pharm Biomed Anal 51:471-477. https://doi.org/10.1016/j.jpba.2009.02.033

45. Prasad KN, Yang B, Zhao M et al (2010) Effects of high pressure or ultrasonic treatment on extraction yield and antioxidant activity of pericarp tissues of longan fruit. J Food Biochem 34:838-855. https://doi.org/10.1111/j.1745-4514.2010.00335.x

46. Prasad NK, Yang B, Zhao M, Wang BS, Chen F, Jiang Y (2009) Effects of high-pressure treatment on the extraction yield, phenolic content and antioxidant activity of litchi (Litchi chinensis Sonn.) fruit pericarp. Int J Food Sci Technol 44:960-966. https://doi.org/ 10.1111/j.1365-2621.2008.01768.x

47. Corrales M, García AF, Butz P, Tauscher B (2009) Extraction of anthocyanins from grape skins assisted by high hydrostatic pressure. J Food Eng 90:415-421. https://doi.org/10.1016/j.jfoodeng. 2008.07.003

48. Senanayake NSPJ (2013) Green tea extract: chemistry, antioxidant properties and food applications - a review. J Funct Foods 5:15291541. https://doi.org/10.1016/j.jff.2013.08.011

49. Rice-Evans CA, Miller NJ, Paganga G (1997) Antioxidant properties of phenolic compounds. Trends Plant Sci 2:152-159. https:// doi.org/10.1016/S1360-1385(97)01018-2

50. Siripatrawan U, Vitchayakitti W, Sanguandeekul R (2013) Antioxidant and antimicrobial properties of Thai propolis extracted using ethanol aqueous solution. Int J Food Sci Technol 48:22-27. https://doi.org/10.1111/j.1365-2621.2012.03152.x

51. Xi J, Shouqin Z (2007) Antioxidant activity of ethanolic extracts of propolis by high hydrostatic pressure extraction. Int J Food Sci Technol 42:1350-1356. https://doi.org/10.1111/j.1365-2621.2006. 01339.x

52. Prasad KN, Yang B, Zhao M et al (2009) Application of ultrasonication or high pressure extraction of flavonoids from litchi fruit pericarp. J Food Process Eng 32:828-843. https://doi.org/10. 1111/j.1745-4530.2008.00247.x

53. Rocha-Santos TAP, Rodrigues D, Freitas ANAC et al (2017) Bioactive polysaccharides exctracts from Sargassum muticum by high hydrostatic pressure. J Food Process Preserv 41:1-12. https:// doi.org/10.1111/jfpp. 12977

54. Li L, Xu J, Mu Y, Han L, Liu R, Cai Y, Huang X (2015) Chemical characterization and anti-hyperglycaemic effects of polyphenol enriched longan (Dimocarpus longan Lour.) pericarp extracts. J Funct Foods 13:314-322

55. Huang G, Wang B, Lin W et al (2012) Antioxidant and antiinflammatory properties of Longan (Dimocarpus longan Lour.) pericarp. Evid Based Complement Alternat Med 2012:1-10. https://doi.org/10.1155/2012/709483

56. Jia L, Jin H, Zhou J, Chen L, Lu Y, Ming Y, Yu Y (2013) A potential anti-tumor herbal medicine, corilagin, inhibits ovarian cancer cell growth through blocking the TGF- $\beta$ signaling pathways. BMC
Complement Altern Med 13:1-11. https://doi.org/10.1186/14726882-13-33

57. Leischner C, Burkard M, Pfeiffer MM, Lauer UM, Busch C, Venturelli S (2016) Nutritional immunology: function of natural killer cells and their modulation by resveratrol for cancer prevention and treatment. Nutr J 15:1-12. https://doi.org/10.1186/s12937016-0167-8

58. Salla S, Sunkara R, Ogutu S, Walker LT, Verghese M (2016) Antioxidant activity of papaya seed extracts against $\mathrm{H}_{2} \mathrm{O}_{2}$ induced oxidative stress in HepG2 cells. LWT-Food Sci Technol 66:293297. https://doi.org/10.1016/j.lwt.2015.09.008

59. Mi L, Wang X, Govind S, Hood BL, Veenstra TD, Conrads TP, Saha DT, Goldman R, Chung FL (2007) The role of protein binding in induction of apoptosis by phenethyl isothiocyanate and sulforaphane in human non - small lung cancer cells. Cancer Res 67: 6409-6417. https://doi.org/10.1158/0008-5472.CAN-07-0340

60. Alexandre E, Araujo P, Duarte M et al (2017) High-pressure assisted extraction of bioactive compounds from industrial fermented fig by-product. J Food Sci Technol 54:2519-2531. https://doi.org/10.1007/s13197-017-2697-2

61. Palaniyandi SA, Damodharan K, Lee KW, Yang SH, Suh JW (2015) Enrichment of ginsenoside Rd in Panax ginseng extract with combination of enzyme treatment and high hydrostatic pressure. Biotechnol Bioprocess Eng 20:608-613. https://doi.org/10. 1007/s12257-014-0857-z

62. Palaniyandi SA, Suh J-W, Yang SH (2017) Preparation of ginseng extract with enhanced levels of ginsenosides Rg1 and Rb1 using high hydrostatic pressure and polysaccharide hydrolases. Pharmacogn Mag 13:124-147. https://doi.org/10.4103/09731296.203992

63. Kim JH, Park Y, Yu KW, Imm JY, Suh HJ (2014) Enzyme-assisted extraction of cactus bioactive molecules under high hydrostatic pressure. J Sci Food Agric 94:850-856. https://doi.org/10.1002/ jsfa.6317

64. Parvez S, Malik K, Ah Kang S, Kim H-Y (2006) Probiotics and their fermented food products are beneficial for health. J Appl Microbiol 100:1171-1185. https://doi.org/10.1111/j.1365-2672. 2006.02963.x

65. Lee H-Y, He X, Ahn J (2010) Enhancement of antimicrobial and antimutagenic activities of Korean barberry (Berberis koreana Palib.) by the combined process of high-pressure extraction with probiotic fermentation. J Sci Food Agric 90:2399-2404. https://doi. org $/ 10.1002 /$ jsfa. 4098

66. He X, Kim S-S, Park S-J, Seong DH, Yoon WB, Lee HY, Park DS, Ahn J (2010) Combined effects of probiotic fermentation and highpressure extraction on the antioxidant, antimicrobial, and antimutagenic activities of deodeok (Codonopsis lanceolata). J Agric Food Chem 58:1719-1725. https://doi.org/10.1021/ jf903493b 